\title{
THE FEASIBILITY OF A CCD FOR AN ASTROMETRIC REFRACTOR
}

\author{
A. R. Upgren, Alice Morales, Jose Herrero, J. W. Griese, III, J. M. Vincent \\ Van Vleck Observatory \\ and John T. Lee \\ Yale University Observatory
}

The $0.5 \mathrm{~m}$ refracting telescope of the Van Vleck Observatory has been active in the determination of trigonometric parallaxes since its first observations in 1922. Its lenses were ground by C.A.R. Lundin of the Alvan Clark Co. for photographic use. Coma was minimized across the field and vignetting was also kept to a minimum. Partly as a consequence the focal curve is very steep in the blue and green regions of the spectrum, as is shown in Fig. 1. A Wratten No. 12 minus blue filter is used to filter out all wavelengths to the blue of about 5200 $\AA$. The region between $5200 \AA$ and $6000 \AA$ is very flat with the focal plane varying over a range of about one millimeter. Towards the red region it steepens, although not enough to impair images on photographic plates of emulsion types 103a-D and IIIa-F, the two in widespread use in recent years.

A CCD of 2048 by 2048 pixels with sensitivity limited to the flat yellow spectral region should allow the telescope to reach stars brighter than visual magnitude 14.5 , the present photographic limit, yet should provide a sufficient reference frame. Table 1 shows the manufacturer's specifications for five typical CCD's of this size. The dimensions of the pixels, the linear and angular sizes and the area covered are shown in the first four columns. The final two columns give the average number of reference stars for the field areas shown, that are brighter than 14.5 for fields in the galactic plane and poles, respectively. It would appear that a judicious choice among the CCD's should be made to assure rich reference frames for all star fields.

TABLE 1

List of Most Probable CCD's (2048² array)

\begin{tabular}{|c|c|c|c|c|c|}
\hline $\begin{array}{l}\text { Pixel } \\
\text { size }\end{array}$ & $\begin{array}{l}\text { Linear } \\
\text { size }\end{array}$ & $\begin{array}{l}\text { Angular } \\
\text { size }\end{array}$ & $\begin{array}{l}\text { Field Size } \\
\text { sq degrees }\end{array}$ & $\begin{array}{c}\text { Average } \\
b=0^{\circ}\end{array}$ & $\begin{array}{l}\text { \# Stars } \\
\mathrm{b}=90^{\circ}\end{array}$ \\
\hline $09.0 \mu \mathrm{m}$ & $18.4 \mathrm{~mm}$ & n $07.5^{\prime}$ & 0.016 & 10 & 2 \\
\hline $15.0 \mu \mathrm{m}$ & $30.7 \mathrm{~mm}$ & n $12.6^{\prime}$ & 0.044 & 26 & 5 \\
\hline $13.5 \mu \mathrm{m}$ & $27.6 \mathrm{~mm}$ & n $123^{\prime}$ & 0.042 & 25 & 5 \\
\hline $12.0 \mu \mathrm{m}$ & $24.6 \mathrm{~mm}$ & n $10.0^{\prime}$ & 0.028 & 17 & 3 \\
\hline $24.0 \mu \mathrm{m}$ & $49.2 \mathrm{~mm}$ & n 20.0' & 0.111 & 67 & 13 \\
\hline
\end{tabular}




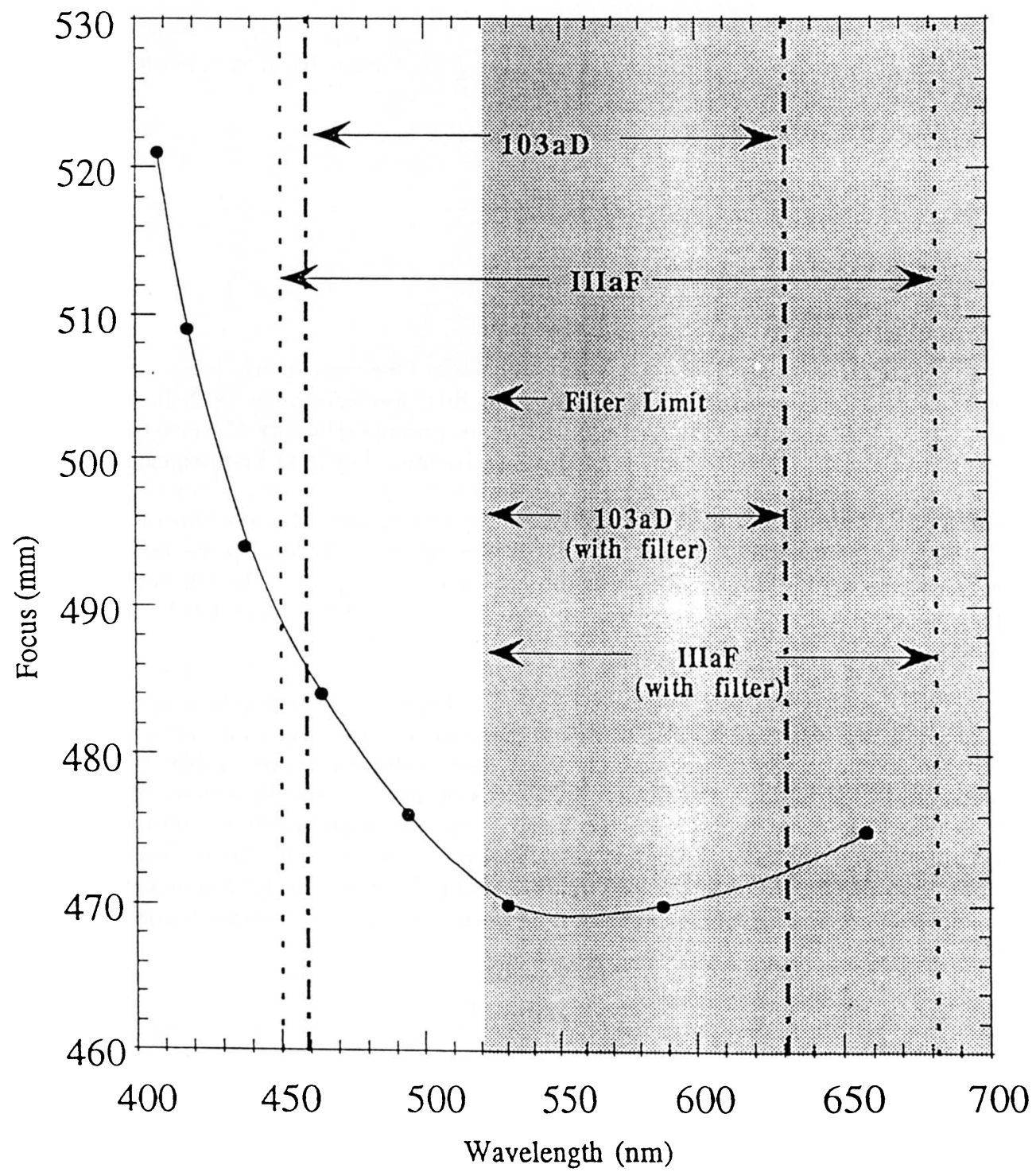

Fig. 1. The focal curve for the $0.50-\mathrm{m}$ refractor. The unshaded portion corresponds to the spectral region blocked by the Wratten filter. Within the shaded portion the wavelengths covered by two emulsions are shown.

This study is supported by Research Grant AST-9218605 and amendments from the National Science Foundation. 